\section{References}

1. Kilian E, Oberhoffer M, Gulbins H, Uhlig A, Kreuzer E, Reichart B. Ten years experience in aortic valve replacement with homografts in 389 cases. J Heart Valve Dis. 2004;13:554-9.

2. Hopkins RA. Freehand aortic valve replacement with aortic allograft valve transplant aortotomy. In: Hopkins RA, ed. Cardiac reconstructions with allograft tissues. New York: Springer-Verlag; 2005. p. 275-99.
3. Ross DN. Application of homografts and clinical surgery. J Card Surg. 1987;2:175-83.

4. Schoen FJ. Are immune mechanisms important in tissue heart valve failure? A debate. J Heart Valve Dis. 2001;10:458-9.

5. Wolfinbarger L, Brockbank K, Hopkins RA. Application of cryopreservation to heart valves. In: Hopkins RA, ed. Cardiac reconstructions with allograft tissues. New York: Springer-Verlag; 2005. p. $133-60$.

\title{
An alternative approach for chest drainage after cardiac surgery: Redon drains
}

Marek Gwozdziewicz, MD, PhD, Petr Nĕmec, MD, PhD, and Andrea Steriovsky, MD, Olomouc, Czech Republic

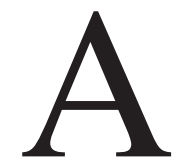

$t$ the end of every cardiac procedure, two or three chest tubes $(28 \mathrm{~F}-32 \mathrm{~F})$ are typically placed in the mediastinum to continuously monitor postoperative blood loss and to prevent undesirable blood collection, especially in the pericardial space, which could potentially lead to cardiac tamponade. The chest tubes are connected to various drainage systems that use the underwater valve seal principle. Suction of about $-20 \mathrm{~cm} \mathrm{H}_{2} \mathrm{O}$ is usually applied.

Here we present an alternative drainage system that provides distinct advantages over the commonly used systems.

\section{Technique}

The drainage system consists of four or five Redon (B. Braun Melsungen AG, Melsungen, Germany) drains (2-mm inner diameter). Each drain is connected to a $600-\mathrm{mL}$ reservoir with an applied suction of $-800 \mathrm{mbar}\left(816 \mathrm{~cm} \mathrm{H}_{2} \mathrm{O}\right)$ (Figure 1). They are placed into the pericardial space (and pleural cavity, if needed) in the following sequence (Figure 2):

1. Drain 1 is positioned along the right heart border (right atrium), ending under the ascending aorta.

2. Drain 2 is positioned in front of the heart directly beneath the sternum.

3. Drain 3 is positioned along the diaphragmatic surface of the heart, ending over the lateral wall of the left ventricle.

From the Department of Cardiac Surgery, University Hospital, Olomouc, Czech Republic.

Received for publication June 20, 2007; revisions received Aug 28, 2007; accepted for publication Sept 14, 2007.

Address for reprints: Marek Gwozdziewicz, MD, PhD, University Hospital Olomouc, I. P. Pavlova 6, 77515 Olomouc, Czech Republic (E-mail: gwozdziewicz@email.cz).

J Thorac Cardiovasc Surg 2008;135:216-7

$0022-5223 / \$ 34.00$

Copyright $\odot 2008$ by The American Association for Thoracic Surgery doi:10.1016/j.jtcvs.2007.09.005
4. Drain 4 is positioned in front of the heart (right ventricle), curving behind the pulmonary artery and ending in the sinus transversus.

5. Drain 5 (pleural, only if needed) is placed into the

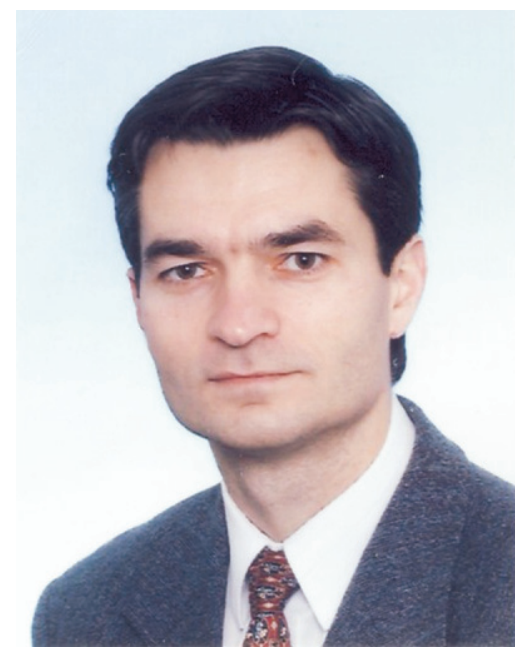

Dr Gwozdziewicz desired pleural space through a cauterized hole in the back wall of the pericardial sac, ending over the diaphragm.

All drains exit the mediastinum through the abdominal fascia in the epigastric area.

Drains are removed on the second postoperative day, being first disconnected from the reservoir to ensure that no continuous suction is applied during their removal.

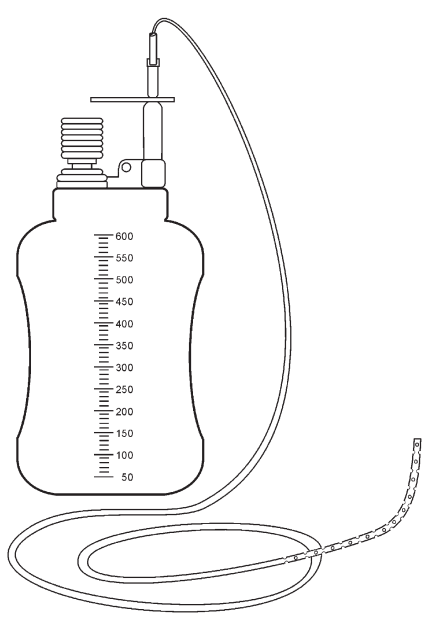

Figure 1. Redon drain with the reservoir. 


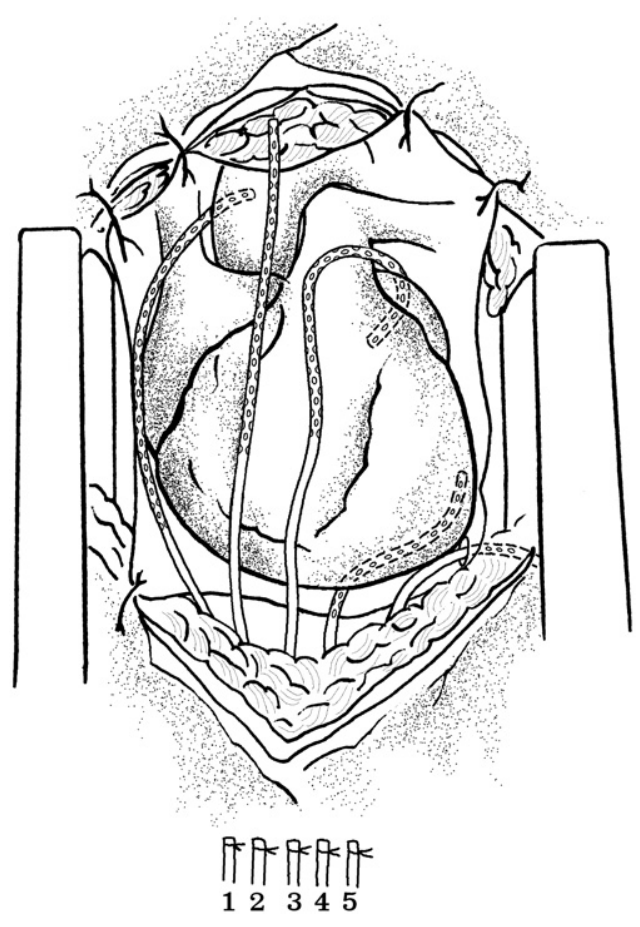

Figure 2. Arrangement of the drains in the mediastinum.

\section{Discussion}

A total of 4297 cardiac procedures were performed between February 2002 and January 2007 at our institution. Redon drains were used for postoperative blood drainage in all cases $(99.8 \%)$, regardless of the type of operation, with the only exceptions being 9 patients in whom it was not possible to control the coagulation disorder after weaning from cardiopulmonary bypass and who therefore required the use of a cell salvage device immediately after the procedure in the operating room and subsequently in the intensive care unit. Chest tubes (32F) were used in these 9 patients.

The postoperative total blood losses at the time of Redon drain removal (usually on postoperative day 2) are summarized in Table 1. Postoperative bleeding complications for the cohort of 4297 patients in whom a Redon drainage system was used are listed in Table 2.

Below, we summarize our experiences with the advantages and disadvantages of Redon drains relative to standard drainage approaches (using an underwater valve seal).

\section{Advantages}

1. The handling is more convenient. Once the drains are connected and checked for tightness (absence of air leaks), there is no need for further monitoring such as checking the water levels or the functioning of the water valve seal.
TABLE 1. The mean postoperative blood loss at the time of Redon drain removal (National Cardiac Surgery Registry 2002-2006)

\begin{tabular}{lc}
\hline Type of procedure & Blood loss $(\mathbf{m L})$ \\
\hline CABG & 971.3 \\
Valves & 1057.6 \\
Thoracic aorta & 1153.9 \\
Redo & 1497.6 \\
procedures &
\end{tabular}

$C A B G$, Coronary artery bypass grafting.

TABLE 2. Postoperative bleeding complications in patients in whom a Redon drainage system was used $(n=4297)$ (National Cardiac Surgery Registry 2002-2006)

\begin{tabular}{lc}
\hline & No. (\%) of patients \\
\hline Reopening for bleeding & $119(2.8 \%)$ \\
Reopening for tamponade & $29(0.7 \%)$ \\
\hline
\end{tabular}

2. The Redon drainage system allows regions of bleeding to be detected. Each drain covers a specific area around the heart, facilitating the localization of any bleeding sources (eg, coronary suture line or left atrium suture line).

3. It decreases the risk of local tamponade. Positioning the drains over all the heart chambers, especially the right and left atria, decreases the risk of local tamponade.

4. It decreases the risk of coronary graft compression. The drains are thinner and more flexible, decreasing the risk of graft compression.

5. It maintains suction during patient transportation. There is no need for an external source of suction, which enables the suction to be maintained when transporting the patient from the operating room to the intensive care unit.

6. It is noiseless. It produces no bubbling sounds that are disturbing for both medical personnel and the patient.

7. It is cost-effective. The Redon drain system is five times cheaper than drainage using chest tubes.

\section{Disadvantages}

1. The Redon drain system is sensitive to air leaks. The presence of an air leak from the lung tissue will result in inadequate suction, requiring the system to be converted to the underwater drainage principle (external suction).

2. It cannot be used with a cell salvage system. In cases of profound bleeding resulting from coagulation disorder, the system cannot be used with a cell salvage device.

Because of the distinct predominance of the advantages of the described system over its disadvantages, we highly recommend its broader use. 